\title{
Microbrachycephaly-ptosis-cleft lip syndrome
}

INSERM

\section{Source}

INSERM. (1999). Orphanet: an online rare disease and orphan drug data base.

Microbrachycephaly-ptosis-cleft lip syndrome. ORPHA:2511

Microbrachycephaly-ptosis-cleft lip syndrome is characterised by the association of intellectual deficit, microbrachycephaly, hypotelorism, palpebral ptosis, a thin/long face, cleft lip, and anomalies of the lumbar vertebra, sacrum and pelvis. It has been described in two Brazilian sisters. Transmission appears to be autosomal recessive. 